\title{
Lazer e meio ambiente: percepções de escolares e de coletores de caranguejo de Barra Nova/ES
}

\author{
José Luiz dos Anjos *
}

\begin{abstract}
Resumo: Este estudo tem como objetivo analisar a percepção de pescadores de caranguejo tendo como escopo o que os "catadores" de caranguejo fazem e realizam em seus tempos livres. O estudo intenta identificar o local de trabalho e de lazer, imbricando o cenário das relações, na evidência de que os espaços podem ser transformados a partir da percepção dos sujeitos. O lazer se traduz numa ação voluntária, pois se trata, segundo os catadores, da percepção do tempo e do espaço estruturados para obtenção do lazer.
\end{abstract}

Palavras-chave: Lazer. Trabalho. Educação. Educação Física.

\section{INTRODUÇÃo}

$\mathrm{O}$ entendimento que tem orientado e explica a "questão ambiental" é a lógica que move o conhecimento acadêmico, ou seja, o conhecimento sistematizado, pautado nos vieses utilitarista $\mathrm{e}$ produtivista. Procurando romper com outras formas de entender e mesmo prescrever a conduta humana, o saber escolarizado volta-se para perceber e propor possibilidades do uso dos espaços ambientais de forma sustentável, sem agredir a continuidade da vida natural.

$\mathrm{Na}$ educação, nas últimas décadas, presenciaram-se temas emergentes sobre o meio ambiente, tendo como escopos propostas existentes nas agendas internacionais e nacionais. Nas agendas, discutem-se as possíveis políticas voltadas para os impactos do desenvolvimento industrial nos ecossistemas, a emissão de gases poluentes e a possibilidade de subsídios de novas tecnologias energéticas menos agressivas ao meio (BRYON, 2004).

\footnotetext{
* Professor Adjunto. Departamento de Desportos. Doutor em Ciências Sociais. Membro do Centro de Estudos em Sociologia das Práticas Corporais e Olímpicos. Universidade Federal do Espírito Santo. Vitória, ES, Brasil. E-mail: jjluanjos1@hotmail.com.
} 
Para a Educação Física, o estudo das relações entre homem e natureza vem recebendo, atualmente, diferentes abordagens, assim como vem se multiplicando a variedade de referenciais teóricos e de práticas metodológicas. Alvo de estudos pela Sociologia e Antropologia, essa atenção recebe da Educação Física determinadas intervenções teóricas, devido ao crescimento de praticantes de esportes radicais e esportes da natureza, assim denominados por autores que teorizam nessa área.

Estudando a produção teórica acerca das práticas corporais, lazer e meio ambiente, vê-se que os estudos centram suas atenções em denunciar as articulações de consumo do mundo capitalista com os praticantes e vivenciadores das práticas corporais realizadas na natureza. Nessa mesma linha, as metodologias empregadas analisam os discursos de praticantes de esportes da natureza, generalizando o sujeito ou observando-o no âmbito de gênero, idade, profissão ou localização geográfica. O eixo e as relações entre corpo $x$ meio ambiente e práticas corporais não constitui um trinômio de estudos dessas produções. Devido à intervenção que exerce sobre a sociedade e como ela o entende, o lazer tem sido objeto de diversificadas análises, muitas vezes, vinculadas ao campo da política e das relações econômicas.

A discussão acadêmica acerca do lazer e do meio ambiente tem seus eixos pautados nos objetos que possam ser analisados e criticados à luz de referenciais da Sociologia, da Antropologia e da Filosofia, fornecendo elementos claros para sua contextualização. Assim, o lócus de discussão fornece condições para analisar o lazer e o meio ambiente, pautados e abordados de acordo com as instituições que promovem programas estruturados no modelo de consumo, no qual os esportes, práticas corporais e a relação com o meio ambiente são promovidos pelos meios de produção do lazer que, avalizados pela mídia, fornecem condições de usufruí-los conforme o poder de consumo do cidadão.

Neste estudo, a proposta é analisar o lazer estrutural da comunidade de Barra Nova, localizada em Guriri, distante 218 quilômetros

Movimento, Porto Alegre, v. 15, n. 03, p. 315-332, julho/setembro de 2009. 
de Vitória, Capital do Espírito Santo. Devido às particularidades que cerceiam a análise do que os "catadores" de caranguejo fazem e realizam em seus tempos livres, o estudo intenta identificar o local de trabalho e de lazer, imbricando o cenário das relações na evidência de que os espaços podem ser transformados a partir da percepção dos sujeitos, ou seja, da intenção humana. Faz-se necessário explicitar que ir-se-á estender a análise além do que fazem estudantes e "catadores" de caranguejo, tendo em vista apontar as possíveis ideologias veiculadas nos discursos das pedagogias/saberes ambientais.

\section{A VIDA ESTRUTURAL DA COMUNIDADE DE BARRA NOVA}

Barra Nova é um povoado formado por quatro comunidades, na região de São Mateus e Guriri, estando entre essas a comunidade de Barra Nova, objeto desta análise. Em sua maioria, o povoado constitui-se de pequenos agricultores que produzem para a sua subsistência e alto índice populacional acima de 35 anos, devido aos jovens em idade escolar se mudarem para casa de parentes na zona urbana.

Em Barra Nova, a construção das casas não segue uma linha determinada. Cercas e muros quase não podem ser vistos entre uma propriedade e outra. As divisas entre as casas se encontram em alguns arames pregados ou amarrados em pequenos mourões. Grande quantidade de galináceas, nos quintais, pode ser vista, dificultando o controle para quem não é o "dono", devido ao trânsito livre que há entre um quintal e outro.

Quanto à infraestrutura social na comunidade, identifica-se um posto de saúde, um centro comunitário, dois templos religiosos e a Escola Municipal de Ensino Fundamental. O prédio da escola ostenta uma intervenção diacrônica na paisagem com uma construção imponente para o local, com salas de aula que comportam até sessenta estudantes. Com paredes altas, lousas verde-musgo acompanhando a extensão das salas, pode-se interpretar que, ao professor, compete a necessidade de ocupar todo o espaço, para que quem observe possa entender que a matéria está sendo lecionada, conforme revelou alguns estudantes.

Movimento, Porto Alegre, v. 15, n. 03, p. 315-332, julho/setembro de 2009. 


\section{TRABALHO, LAZER E SUAS TRANSFORMAÇõES}

Para conhecer o trabalho que envolve a "cata" do caranguejo na comunidade de Barra Nova e o local de trabalho, realizaram-se entrevistas com moradores e estudantes da comunidade. Foram informantes, oito sujeitos, todos moradores na comunidade, sendo três homens (dois pescadores e um trabalhador rural, quatro mulheres casadas, um menino de dez anos e um grupo de estudantes da $8^{\mathrm{a}}$. série da escola da comunidade. As entrevistas foram diretas, abertas, realizadas nos terraços e quintais das casas dos próprios informantes e em uma sala de aula da escola da comunidade. Esteve-se no local em três oportunidades. Na primeira, para conhecer a região, e, na segunda e terceira, para realizar as entrevistas.

Iniciou-se a pesquisa procurando saber quem era "catador de caranguejo". O primeiro informante revela que é "pescador durante toda vida" e de carteirinha, como todo "catador". E esse documento que diz se o catador é ou não "catador registrado". Aqui, a burocracia se faz presente, não se trata de um ofício em que o "catador" se apresenta sem nenhuma relação com as estruturas burocráticas do trabalho.

Alves e Nishida (2003), estudando os aspectos econômicos e ambientais dos catadores de caranguejo-uça de Mamanguape - PB -, constataram que os catadores constituem uma categoria ainda bastante desmobilizada, pois, geralmente, não fazem parte de nenhuma cooperativa ou associação. O mesmo foi confirmado por Maneschy (apud ALVES; NISHIDA, 2003), observando os catadores de caranguejo do Pará. Esse autor argumentou que a desmobilização se traduz na imagem desvalorizada incorporada do trabalho que realizam na sociedade. Esse estado político observado pelos autores se difere do que se encontra em Barra Nova, em relação ao estágio de mobilização político-associativa.

Em seguida, pergunta-se o que faz com que uma pessoa seja um "catador" sem ter o registro de pescador. As respostas foram lacônicas: "Para ser catador tem que gostar", "Você deve gostar do mangue [...]. O mangue é a sua segunda casa". São respostas que

Novimento, Porto Alegre, v. 15, n. 03, p. 315-332, julho/setembro de 2009. 
apontam uma relação direta entre o local de trabalho e o sujeito, não sendo possível identificar uma relação distinta do "catador" com o local de trabalho.

A configuração da indistinção espacial também é social e podese identificá-la quando se elabora a pergunta: quando chegou a energia elétrica, a construção da Escola, o início do serviço de transporte urbano na comunidade? Para essas perguntas que envolviam datas ou épocas, os informantes não responderam de forma precisa, atribuindo ao tempo ordens sazonais que têm influência na comunidade, como épocas de cheias e períodos de secas.

O antropólogo Evans-Pritchard, quando descreve o modo de vida dos nuers, no Sudão, inaugura uma teoria reflexiva acerca do sistema cronológico de grupos tribais. Os nuers possuem a cronologia pela ação climática, ou seja, pelo "[...] domine par le rythime des saisons" (PRITCHARD, 1968, p. IV). Assim, o tempo é datado e narrado pelos ritmos das cheias, da seca, da terra úmida e da produção. Percebe-se que os aspectos físicos materiais se transformam em aspectos sociais.

A população da região é estratificada e há indicações de grupos. Não se observa a população como um conjunto dos grupos, mas há as frações de cada grupo, discriminado e identificado, seja pelos comportamentos, seja pelas idades que cada grupo apresenta. Assim, perguntando quantas pessoas se estabelecem na comunidade de Barra Nova, as respostas apontaram que "[...] tem muita gente aqui... o que tem de crianças... Tem muita criança, gente nova... rapazes e mocinhas, também".

Nas respostas, a comunidade constitui o que chama-se na Antropologia de Evans-Pritchard, teoria de grupo estrutural, pois não entende a comunidade formada por indivíduos, mas por grupos como Evans-Pritchard encontrou nos Nuers, revelando um fenômeno dos aspectos de filiação de grupo. Portanto, trata-se de uma reflexão em que as respostas apontam uma comunidade estruturada em grupos. Não se fala da comunidade estruturada sob uma população, de um contingente. Fala-se da comunidade estruturada e distinta em seus comportamentos, gêneros e ocupações; é o coletivo que caracteriza o

Movimento, Porto Alegre, v. 15, n. 03, p. 315-332, julho/setembro de 2009. 
sujeito pertencendo a um determinado espaço demarcado pelas relações que estabelecem e se identificam por certo grau de pertencimento a este ou àquele grupo. $\mathrm{O}$ sujeito individualizado traduz o seu pertencimento ao grupo quando se relaciona com o coletivo, apontando características como um ato distintivo de pertencimento ou de relações sociais que indiquem a que grupo pertence ou com qual se relaciona criando e construindo microrrelações sociais.

Na relação "catador" e mangue, quem disciplina as relações são as informações que chegam do Instituto Brasileiro do Meio Ambiente e dos Recursos Naturais Renováveis (IBAMA). Os informantes explicam que antes se podia "catar" o caranguejo em qualquer época, "[...] Mas hoje, não".

A doença que ataca o caranguejo não é o único problema de Barra Nova. Fatores climáticos fazem oposição à vida dos nativos dessa comunidade. O tempo é sazonal, e a conotação ecológica determina o ritmo de vida e de trabalho de Barra Nova: se é seca, a agricultura não "dá trabalho"; se é cheia, "mata tudo... tudo fica afogado"; e se é época da "andada... a gente vai pra roça".

As informações passam a fluir quando um informante fala sobre a forma de cata do caranguejo [...] "antes a gente catava na mão... era no braço... hoje ficou mais difícil, é na redinha. Você vai até lá arma a redinha e depois vem catando os bichos".

Perguntou-se por que o uso da redinha, e Zé Coco explica: "Cada vez mais o caranguejo faz os buracos mais fundos e não tem jeito mais de você pegar". O uso "do braço", tão-somente uma extensão do corpo, cedeu lugar a alguns instrumentos: o enxadão, a redinha e o gancho. Não se trata aqui de instrumentos tecnológicos, produto da tecnologia moderna, mas de um meio acessível, construído pelos próprios trabalhadores diante de uma situação de necessidade de atendimento aos contratos firmados, mesmo que, tacitamente, com os agentes atravessadores.

As explicações dadas para o uso da "redinha", que é ilegal, têm relação direta na própria ação dos caranguejos, como meio de sobrevivência, pois, segundo o informante:

Movimento, Porto Alegre, v. 15, n. 03, p. 315-332, julho/setembro de 2009. 
Uns 15 anos atrás... pra cá... os caranguejos vêm fazendo buraco mais fundo e não tem mais jeito de catar no braço... aí tem que ser na redinha mesmo. Mas o IBAMA não permite... Mas a gente não pode parar... é que sempre vem mais pedido, ou é eles ou é nós.

A relação homem $x$ mangue é observada e os "catadores" percebem a agressão causada à natureza. Compreendem que a extração do caranguejo de seu habitat e as dificuldades de a natureza "recompor" as vidas dela retiradas é a imposição de uma produção cada vez maior. Essa situação é constatada quando o entrevistado afirma: "Sempre vem mais pedido", e a demanda de consumo provindo do mundo urbano é que estabelece a relação entre o homem e a natureza. Assim, compreendem os "catadores" que, mesmo criando normas e procedimentos que estabelecem apropriação e ocupação dos espaços "Um dia teremos que escolher entre nós e o mangue", conforme documento distribuído pela Associação dos Catadores de Caranguejo de Barra Nova, numa das reuniões da comunidade.

\section{PAPEL DA ESCOLA E AS AÇõES HUMANAS}

Para os "catadores" e os estudantes, grupos de pessoas vindos da cidade para visitar o mangue e "passando algumas horas catando caranguejo, está cada vez mais aumentando". Trata-se de programas e passeios denominados "passeios ecológicos", agendadas por empresas que oferecem programas de lazer, e têm como destino as pousadas que ficam na região de Barra Nova. Entre as diversas atividades, há a visita ao mangue, orientada por guias, e a possibilidade de uma aproximação do homem urbano com os espaços do mangue.

Entre as diversas programações realizadas e oferecidas pelas empresas, percebe-se, conforme explica uma professora da escola da comunidade, que não há uma preparação dos guias ou dos consumidores dessas programações de lazer para respeitar a relação que se deve ter com o mangue. Embora não haja uma preparação, percebe-se, com referência aos visitantes urbanos, certo ar de "espaço

Movimento, Porto Alegre, v. 15, n. 03, p. 315-332, julho/setembro de 2009. 
sagrado", onde o respeito à natureza se traduz em comportamentos hierarquizados de princípios, ou seja, obedecem às normas estabelecidas para o meio, pois são sabedores da degradação promovida pela ação humana.

Para estabelecer a relação escola $x$ comunidade e a interlocução com os visitantes, a partir de 2003, na escola da comunidade, passaram a figurar, entre os projetos pedagógicos, conhecimentos acerca do meio ambiente e da relação homem $x$ vida ambiental. Três programas de conscientização constituem o projeto das aulas de meio ambiente e a inter-relação com as disciplinas, entre essas: Geografia, Ciências e Educação Física.

$\mathrm{Na}$ escola, a via para entender o meio ambiental trouxe consequências positivas, pois, diante da fragmentação e do confinamento, o saber ambiental no ensino superior vem se tornando cada vez mais especializado e menos inteligível para o público externo. A escola passou a contar com temas tipicamente interdisciplinares, em que todas as disciplinas podem, mediante seu objeto de ensino, participar das diversas tomadas de situações. A consciência de que alguns problemas emergenciais da humanidade não se resolvem isoladamente, como a escassez mundial da água potável, as tragédias ambientais entre derramamentos de petróleo, lixos, vazamentos nucleares e seus efeitos colaterais, são exemplos que todas as disciplinas podem abordar em seus respectivos campos de conhecimento. A posição assumida pela escola, em lidar com o conhecimento interdisciplinar, assume outra dimensão, na medida em que fica evidente o imperativo de tratar o meio ambiente dentro de enfoques interdisciplinares. Isso rompe com paradigmas cristalizados no contexto escolar. Um exemplo dessa posição assumida foi o que constataram-se nos planejamentos das disciplinas de Geografia, Ciências, História e Educação Física.

Voltando aos projetos, esses têm como objetivos, preliminarmente, estimular e conscientizar os "catadores" de caranguejo a conservarem o mangue. Essa "conscientização" tratada faz referência ao mangue e à sua natureza produtiva, como possibilidade de fonte esgotável e não renovável. Percebe-se uma complexidade na abordagem pelas disciplinas dessa relação homem e exploração $x$ natureza e

Movimento, Porto Alegre, v. 15, n. 03, p. 315-332, julho/setembro de 2009. 
meio ambiente. Essas categorias e conceitos formam debates e pontos de divergências na transversalidade das disciplinas que acentuam a relação ação humana no espaço do mangue/natureza. Nessa mesma linha de discussão, há pedidos de esclarecimento dos afiliados à Associação da Comunidade. Quanto à possibilidade dos reflexos modernos no espaço de trabalho dos "catadores" também constituem pontos de convergências e divergências nas relações da ação humana no espaço de trabalho.

\subsection{Os projetos das disciplinas} módulos:

Os projetos das disciplinas escolares se consubstanciam em três

a) reunião da comunidade de educadores da escola com a Associação de Pescadores de Barra Nova: trata-se de identificar os principais pontos que afetam diretamente o mangue e seus sistemas de continuidade de intravida manguezal. Entre esses, figuram o lixo acumulado no mangue trazido pela corrente do rio Mariricu e a pesca predatória de caranguejos fêmea por catadores de outras regiões. Essa preocupação é identificada principalmente nos planejamentos da disciplina de Ciências. Procura enfocar os períodos sazonais de reprodução dos caranguejos, conforme observou-se na fala dos pescadores. Esse respeito à natureza decorre da necessidade de manter a continuidade do sistema e da cadeia de reprodução, pois é do mangue que grande parte das famílias busca sua subsistência;

b) constituição do grupo "pró-mangue": aqui figura a relação da comunidade escolar com o trabalho. Não podemos afirmar que as atividades a serem desenvolvidas pelos estudantes como guias se constituem como trabalho, pois, conforme nos informa a professora de Ciências da Escola, "Os estudantes têm essa atividade como lazer". Não há uma relação direta entre os grupos que visitam o mangue com os estudantes da escola. A intermediação fica por conta da Associação dos Pescadores de Caranguejo com os coordenadores dos grupos turísticos. Esse projeto ficou a cargo da disciplina de Educação Física, já que, segundo consta no planejamento do projeto dessa disciplina, as atividades: mangue e grupo de visitas e deslocamentos pelo mangue

Movimento, Porto Alegre, v. 15, n. 03, p. 315-332, julho/setembro de 2009. 
se constituem como lazer, logo "[...] a disciplina escolhida para programar e formar o grupo pró-mangue e de limpeza foi a Educação Física e Ciências". No entanto, os estudantes recebem conhecimentos de outras áreas que transversalizam tematicamente. A disciplina Educação Física desponta como instrumento de reaproximação do homem urbano com natureza e abre possibilidade de reestruturação do conhecimento ambiental nas outras disciplinas. $\mathrm{O}$ trato do conhecimento, que implica método de aprendizagem, merece reflexões a partir da aplicabilidade do conhecimento quanto à efetivação do projeto "Guias do Mangue". O que difere a Educação Física das demais propostas é que seu projeto transcende à sala de aula. Está voltado para atender a uma demanda da comunidade externa (visitantes) e sua relação com o mangue, permitindo a aproximação dos não nativos com a natureza, sem agredi-la;

c) vida no mangue: constitui o programa da disciplina de Ciências para os estudantes da $8^{\text {a }}$. série dessa Escola. A identificação de ramos, vegetações e arbustos que as disciplinas de Geografia e Ciências têm como conteúdo e transversalizam constitui o escopo maior desse projeto. Os projetos preveem meios alternativos para que a pesca predatória não destrua a continuidade da vida do manguezal. O lixo deixado pelos próprios "catadores", instrumentos de "caça", como a redinha e as garrafas descartáveis, são os principais causadores da degradação do mangue, segundo os "catadores". O projeto prevê, a cada vinte ou trinta dias, uma programação de estudantes da $8^{\mathrm{a}}$. Série, em conjunto com os "catadores", para uma limpeza no mangue.

\section{DISCURSOS PRODUZIDOS PELA PEDAGOGIA LIBERAL}

Merece uma reflexão acerca do espaço, tempo e ação humana o discurso do saber sistêmico. O discurso acadêmico acerca da questão ambiental vem se renovando, apontando diferentes conceitos e categorizações discursivas. Para Santos (1996), o discurso ambiental produz metáforas. Produzem-se conceitos que reproduzem o discurso ideológico. Ideológico e limitativo, pois preconiza caracterizações de relacionamento com a natureza. Chama-se de natureza os espaços que ainda não foram apropriados, demarcados e não sofreram a

Movimento, Porto Alegre, v. 15, n. 03, p. 315-332, julho/setembro de 2009. 
ação humana no sentido de expropriar o que, em curto prazo, poderá ser esgotável. O meio ambiente traduz-se no que o homem conhece da natureza, os espaços demarcados que vêm sendo alvo de recuperação. Com efeito, a limitação existe, pois não há relação real do homem com a natureza, já que não há subjacências recíprocas nas relações desencadeadas pelo homem na natureza.

Para Santos (1996), natureza é o espaço não ocupado pelo homem com finalidades subjacentes, independentemente de suas ações. O homem se relaciona com uma sociedade cheia de espaço, e a natureza possui esses espaços procurados pelo homem. Textualmente, entende-se por natureza o que ainda não foi consumido, ocupado e explorado. Essa relação que as disciplinas pedagogizadas procuram evocar entre homem-natureza trata-se de uma relação que ainda não existe; o que há é uma ação discursada pelas disciplinas pedagogizadas de apelo do homem na ocupação dos espaços da natureza. Não há dialética do homem com algo que não tem finalidade recíproca, daí denominarmos de natureza o que os discursos pedagogizados chamam de meio ambiente. A natureza não tem finalidade de interesses, embora o curso ambiental seja marcado pelas relações históricas do homem, ocupando os seus espaços.

O que faz sentido, neste entorno, é que há uma presença humana que se preocupa em usar espaços da natureza para suas finalidades. Nos discursos, aqui traduzidos como saberes pedagogizados, o que existe é uma tentativa de utilizar a natureza sem agredi-la. Nessa tentativa de ocupação da natureza, imprimem-se novas relações, não mais de ocupação do homem nos espaços da natureza, mas de exploração. As atividades esportivas, de lazer e de turismo utilizam os espaços para exploração, elegendo espaços da mercadoria e consumo e, nesse caso, a mídia possui um papel de destaque, dando credibilidade a um discurso equivocado. Preconiza-se mais uma natureza espetáculo, inventada pelos aparelhos de comunicação, com tendências a ocultar a natureza histórica, produto da ação humana ao longo do tempo (SANTOS, 1996). É justamente sobre essa natureza espetáculo que a prática do lazer e turismo procura caminhar transmitindo uma realidade falsa e comprometedora de relação passiva e não conflituosa entre homem e natureza.

Movimento, Porto Alegre, v. 15, n. 03, p. 315-332, julho/setembro de 2009. 
A discussão dessa apropriação promove o desgaste de um meio que é resultante de uma forma de produzir, de ocupar, de usar o planeta. A visão puramente ecológica induz a uma premissa que conduz o desenvolvimento de forma cada vez mais equivocada. É essa a razão pela qual os estudos do meio ambiente são os estudos mais financiados no mundo. Os financiamentos só vão atualmente para os projetos em que não há interesse em evidenciar o atual estado de expropriação da natureza, que não permitem que o mundo perceba a situação em que se encontra o que os projetos modernos de produção fizeram com a natureza histórica (SANTOS, 1996).

Se, de um lado, fica evidente a relação de desgaste com o meio, de outro, obscurece a relação da comunidade com o mangue. A estruturação das relações sociais e dos espaços permite a divisão do que é trabalho do que é lazer pela estruturação temporal. Isso fica evidente aos olhos quando possibilita perceber que tantos os estudantes como os nativos de Barra Nova percebem o mangue como espaços de lazer e trabalho, configurando a percepção estabelecida pelo tempo livre e disponível, instituído pelo tempo próprio para produzir ou para dispor de tempo do não trabalho. Mesmo que o trabalho surja dentro do universo do lazer, acaba oferecendo oposição a ele, na percepção dos catadores e estudantes de Barra Nova. Esse discurso fica exposto quando os catadores de caranguejo, assim como os estudantes, percebem que, mesmo "respeitando" o mangue, ou seja, promovendo uma "agressão solidária", e extraindo dele o caranguejo, isso não se tipifica como trabalho. Quanto ao processo de ocupar os espaços do mangue e dele se servir, mas não realizando uma intervenção direta, percebe-se como um tempo da não produção, o que tipifica tempo de não trabalho. Nesse sentido, a exploração dos espaços pelo turismo não constitui uma agressão ao meio, pois não há caracterização de vínculo entre a ocupação dos espaços com a ação humana, entendida como trabalho. São discursos que elaboram novas percepções e noções espaciais distintas, em que a demarcação da ação humana sobre a natureza é estruturada por novos recortes políticos, por percepções sociais e econômicas.

Embora a reflexão aponte para uma situação que se dirige para o trabalho, os estudantes não percebem o seu envolvimento nos projetos

Movimento, Porto Alegre, v. 15, n. 03, p. 315-332, julho/setembro de 2009. 
da escola como um dispêndio de uma dedicação semelhante às obrigações escolares. Essa desvinculação entre lazer e o universo do trabalho não se dá no plano material, mas vem amarrada a diversos valores no plano emocional. Não se trata de uma realização de necessidades sociais, mas de uma mudança de ethos perceptível aos sujeitos que promovem novos valores para suas ações.

\subsection{Percepção espacial: lazer e trabalho}

Parker (1978) analisa o grau de identificação das pessoas com o trabalho e conclui que a relação entre sujeito e trabalho depende da gratificação que ele lhe traz. Há pessoas que priorizam o trabalho e, muitas vezes, encontram nele um grau de satisfação e prazer que outros só encontram no lazer. Essa relação do homem com a natureza e sua gratificação pode ser vista na pesca em alto-mar, conforme informa Deuzimar Santos, 49 anos, nascido na comunidade de Gameleira, próxima de Barra Nova. Ele explica: "Tem dia que você vai pescar de um jeito, mas... daí sopra um vento e você tem que pescar de outro". Continuando, ele diz "Se você volta, porque não deu pra pescar, você faz um servicinho aqui, outro ali... planta... carpe... roça". Para Deuzimar, acompanhado de outras pessoas também pescadoras, se não houve produção/pesca, o que se faz no restante do dia não é trabalho.

Que fatores poderão influenciar a percepção dos "catadores" e dos estudantes da comunidade de Barra Nova?

Ao falar-se do lazer na comunidade, os informantes explicam que o futebol é a atração, de vez em quando, e não fornecem mais detalhes sobre o uso do tempo livre. Essas informações acerca do que fazem aos sábados, domingos e feriados foram obtidas pelas falas dos oito informantes pelos entrevistados. Eles revelam que, aos sábados, domingos e feriados, quando não vão à casa de parentes, vão "[...] consertar a rede, limpar o barco", como uma forma de ocupar o tempo livre. Os informantes explicam: "Catar caracol, conchas que a maré traz pra fazer artesanato" é outra atividade realizada.

Haag (1982), ao teorizar acerca de desporto e tempo livre, faz sua análise amparada em Habermas. O filósofo/sociólogo alemão

Movimento, Porto Alegre, v. 15, n. 03, p. 315-332, julho/setembro de 2009. 
observa três distinções na forma de comportamento do homem no seu tempo livre, estando relacionadas com o trabalho: regenerativa, suspensiva e compensativa. No entanto, Habermas (apud HAAG, 1982), não acredita que, na realidade, o tempo livre possa dar possibilidade compensatória, pois essa fase se mostra muito próxima do trabalho. Habermas faz com que se reflita que o incremento de horas livres, a redução da semana de trabalho ou a extensão de férias ao trabalhador não são suficientes para proporcionar um verdadeiro tempo livre. Percebe-se, nas palavras dos informantes, certa oposição a Habermas, pois não se pode dizer que o trabalho se relaciona e exerce influência sobre o seu tempo livre, no sentido de que este pode ser visto como uma continuação das experiências e atitudes do trabalho. Aqui se observa a percepção dos sujeitos em frente ao mangue, local e espaço de trabalho se convergindo em espaço de lazer. Vê-se que há duas situações determinantes entre a pessoa e a ação: a situação involuntária (trabalho) e a situação voluntária (lazer).

Havendo a distinção entre essas duas situações de relacionamento entre o sujeito e o objeto (trabalho/lazer), é possível ver o mesmo espaço servindo aos sujeitos de forma diferente. Aqui a intencionalidade dos sujeitos distingue a ação humana para algum propósito. Entende-se que toda ação humana é dirigida para um fim, logo, o trabalho, para os "catadores e estudantes" de Barra Nova, possui uma ação instrumental, enquanto o lazer não traduz nem reflete esse propósito. Nesse sentido, as percepções de lazer e trabalho são inversas. Dependendo da percepção, tem-se elementos da ação humana tipicamente subjetiva, em que o lazer configura um fazer subjetivo (intencionalidade consciente), e o trabalho um fazer objetivo (inconsciente), destituído da percepção do sujeito, devido a uma cultura de trabalho já instalada socialmente, em que o trabalho é regido por normas, tempo/período, ação de produção, objetivos propostos e a serem alcançados. Não existindo tais percepções, não há por que "[...] dizer (falar) que isso seja trabalho", quando executa alguma tarefa "fora" do tempo proposto para pescar.

Lazer e trabalho são ações sociais que podem ser distinguidas por atividades racionais, tendo uma finalidade prática em si mesma, ou ambos poderão estar permeados por ações simbólicas. Parece

Movimento, Porto Alegre, v. 15, n. 03, p. 315-332, julho/setembro de 2009. 
que aqui o desenho da discussão vai alcançando os horizontes finais. Mais uma vez, cita-se Habermas ao estabelecer e realçar a oposição entre uma interação alimentada pelas técnicas racionais, subjacentes e instrumentais.

Na medida em que a sociedade atinge um estágio de desenvolvimento tecnológico, consequentemente, o local de trabalho e o de descanso toma situações indistintas. A casa, o lar que constitui o local do descanso, do aconchego, para a sociedade tecnologizada, constitui um local de continuidade do trabalho. As tecnologias, do fax, do computador, da calculadora, da internet, das câmaras de vídeo aproximam cada vez mais locais de trabalho e local de lazer e descanso. No entanto, o lar, a casa, o aconchego não implica o local de prazer. Eis a questão que vem-se perseguindo neste estudo. As ações humanas, carregadas de intencionalidade, se manifestam expressando o que se encontra na intencionalidade objetiva. Logo, o espaço de lazer, o lar, apresenta uma face como possibilidade e aspiração do prazer, portanto, o espaço do mangue, quando lazer, não é percebido como espaço do trabalho.

Analisando as falas dos "catadores/pescadores" e o fazer pedagógico dos estudantes, se é tentado a tratar os casos referidos como atividades contraditórias de lazer, uma vez que pela relatividade com que devem ser avaliados, englobam situações de trabalho ou mesmo atividades que não se englobam no que aqui se entende por lazer, porque são abarcantes de situações laborais. É o caso, por exemplo, da leitura, cozinha, de entretenimento familiar e educação.

\section{Considerações Finais}

Dentre os objetivos propostos, tinha-se como ponto de análise identificar as percepções que apontavam a relação do modo de trabalho dos catadores de caranguejo e o tempo livre disponível para o lazer. Que influências são estabelecidas entre os dois espaços temporais?

Percebe-se que tempo e espaço podem ser vistos, em seu interior, como uma continuação das experiências e atitudes do trabalho. Já o lazer, quanto ao tempo e espaço, pode ser compreendido como

Movimento, Porto Alegre, v. 15, n. 03, p. 315-332, julho/setembro de 2009. 
extensão do trabalho, mas, estruturalmente, os "catadores" e estudantes não atribuem essa conotação, caso o tempo e o espaço estejam fora do contexto de trabalho. Mas a percepção dos sujeitos revela que esses mesmos espaços podem ser transformados de acordo com a relação que se estabelece entre o sujeito com o ambiente de trabalho. A indistinção entre sujeito e ambiente de trabalho, nesse caso, o mangue e o mar, favorece a análise de que os mesmos espaços servem a situações distintas da ação humana. Embora seja posto em prática um conhecimento apreendido na escola, os estudantes não veem como continuidade do trabalho escolar colocá-lo nas ações que realizam no mangue.

Numa outra reflexão, pode-se concluir que os discursos acerca do meio ambiente agem na possibilidade de ideologizar as ações humanas construindo percepções que vingam subjetivamente. Apropriar-se de espaços ambientais/natureza usando o tempo do lazer, da ação humana possibilitada pelo turismo, é um dos discursos impetrados para não se perceber a agressão ao meio. Essa é uma das questões que se entende ser oportuno que as disciplinas Geografia, Ciências e Educação Física discutam. Constitui-se, antes de tudo, num discurso que age silenciosamente, dispondo de mecanismos que não deixam obscurecidas a qualquer tentativa de olhar mais atento para uma situação de mascaramento da degradação ambiental atual.

Foi possível identificar outra face que distingue perfeitamente tempo e espaço para o lazer se transformando em trabalho pela ação humana, mas não perceptível para os sujeitos que foram os interlocutores. Ir ao mangue, ao mar para apanhar conchas e caracóis, para os "catadores" de caranguejo, não se trata de trabalho. Assim como dirigir, guiar e acompanhar grupos urbanos pelo mangue, para os estudantes, não é uma ação instrumental escolar. No entanto, revela que esse tempo é dedicado a uma tarefa seguinte, pois conchas e caracóis, posteriormente, se tornarão artesanatos que se transformarão em produtos, servindo como fonte de renda, e os estudantes serão recompensados pelo "trabalho escolar" realizado. Pergunta-se, então, se subjacente esse lazer pode ser entendido como um trabalho dissimulado? As análises interpretadas revelam que, para a comunidade, o lazer apresenta uma face com possibilidade temporal qualitativa

Movimento, Porto Alegre, v. 15, n. 03, p. 315-332, julho/setembro de 2009. 
não se constituindo uma realidade histórica perceptível na mesma proporção do trabalho. São percepções que, pedagogicamente, precisam ser desconstruídas pela escola.

Finalizando, é, precisamente, na esteira da definição do tempo de trabalho que se traça a diferença entre tempo livre e tempo de lazer. É que, para além de encarar-se o tempo livre como uma espécie de apêndice do tempo de trabalho, dota-se este tempo livre de um sentido utilitário. Sendo assim, uso do tempo livre constitui valores individuais, ou seja, preocupa-se com o que o coletivo pensa acerca do uso do tempo livre. Assim novas atitudes tendem a apoiar-se sobre uma noção quantitativa, mensurável e concreta, mas sempre definida em relação ao trabalho.

O lazer, em contra partida, é de ordem mais qualitativa e subjetiva, postulando um lugar que permanece entre a liberação das tarefas obrigatórias e as tarefas não obrigatórias, percebidas pelo sujeito. A realização de tarefas no tempo de lazer não é percebida como trabalho, ou seja, de forma utilitária e social. Sendo assim, diria-se que pressupondo o lazer, estrutural e perceptivamente não é trabalho, no entanto, o inverso não se verifica. Já o tempo livre tornou-se tempo social, logo, econômico.

Leisure and environment: perceptions of students and collectors of crab Barra Nova/ES Abstract: This study aimed to analyze the perception of work and leisure of the crab fishermen of the community of Barra Nova. The study looks at the place of work and leisure, overlapping the scenario of the relations, where the spaces can be transformed from the perception of the subjects. Leisure is a voluntary action, according to the words of the fishermen and gatherers, as it concerns the perception of structured time and space in order to obtain leisure.

Keywords: Leisure. Work. Education. Physical education.

Movimento, Porto Alegre, v. 15, n. 03, p. 315-332, julho/setembro de 2009. 


\begin{abstract}
Ocio y medio ambiente: percepciones de los estu-diantes y de los recolectores de cangrejo de Barra Nova ES

Resumen: El objetivo de este estudio fue analizar la percepción de trabajo y ocio de los pescadores de cangrejo de la comunidad de Barra Nova. El estudio evidencia el lugar de trabajo y de ocio, gestando el escenario de las relaciones, donde los espacios pueden ser transformados a partir de la percepción de los sujetos. El ocio se traduce en una acción voluntaria según los comentarios de los pescadores y recolectores, ya que se trata de la percepción del tiempo y del espacio, estructurados para la obtención del ocio.

Palabras clave: Ocio. Trabajo. Educación. Educación física.
\end{abstract}

\title{
REFERÊNCIAS
}

ALVES, R. R. N.; NISHIDA, A. K. Aspectos socioeconômicos e ambientais dos catadores de caranguejo-uça do estuário do Rio Mamanguape, Nordeste do Brasil. João Pessoa: Universidade Federal da Paraíba, 2003.

BRYON, E. Terra de mangue (não) é terra de habitar: a subjetividade na produção do espaço do Recife. 230 f. Tese (Doutorado em Serviço Social). Universidade Federal de Pernambuco, Recife, 2003.

BRYON, E.; GEHLEN, V. Conflitos na produção do espaço: um estudo de caso em Gaibu. Disponível em: www.fundaj.gov.br. Acesso em: 14 dezembro 2006.

CATADORES de caranguejo desistem dos mangues. A Gazeta, Vitória, 13 maio, p. 11, 2006

EVANS-PRITCHARD, E.E. Les nuer: description des modes de vie et des institutions politiques d'un peuple nilote. Paris: Gallimard, 1968.

HAAG, H. Deport y tiempo libre. In: $\mathrm{KOCH}$, I. Hacia uma ciência del deporte. B Ayres: Kapelusz, 1982.

PARKER, S. A sociologia do lazer. Rio de Janeiro: Zahar, 1978.

SANTOS, M. A natureza do espaço. São Paulo: Hucitec, 1996.

Recebido em: 20. 08.2007

Aprovado em: 17.06.2008

Novimento, Porto Alegre, v. 15, n. 03, p. 315-332, julho/setembro de 2009. 